\title{
Medical Informatics Meets Medical Education: the Croatian
}

\section{Experience}

\author{
Josipa Kern ${ }^{1}$, Kristina Fišter ${ }^{1}$ \\ ${ }^{1}$ University of Zagreb, School of Medicine, Zagreb, Croatia
}

\begin{abstract}
Objectives: The purpose of this paper is to describe the medical informatics program and training at the University of Zagreb, School of Medicine (Croatia).

Methods: We reviewed the medical informatics program, training and research for medical students at the integrated pre-graduate and graduate level, as well as at the postgraduate education and research level.

Results: We present three approaches to teaching and training medical students in medical informatics at the integrated pre-graduate and graduate level. These are (1) Basics of medical informatics taught early in the medical curriculum, (2) Medical informatics which uses students' clinical knowledge and is taught towards the end of the medical curriculum, and (3) individualized research programs. Both Basics of medical informatics and Medical informatics are courses tailored in line with the IMIA Recommendations on Medical Informatics Education for IT users, and adjusted to students' attitudes to medical informatics issues and the position of the courses in the medical curriculum.
\end{abstract}

Postgraduate studies, as the higher level of education at the School of Medicine, also include several mostly elective medical informatics courses dealing with general medical informatics methodology and health information system management in both clinical medicine and public health. Included are also simulation modeling, methods of machine learning and knowledge discovery in medical domains, as well as medical statistics and methods oriented towards free textual data analysis. The postgraduate level includes in addition telemedicine, electrophysiological methods in research, and evidence based medicine.

Conclusions: Medical students are starting to recognize the role of information in their future profession. They require medical informatics applications to support their professional work with patients, as well as their research. In particular they express interest in machine learning, simulation modeling, medical decision making, data security, e-learning, and evaluation of ICT based medical applications.

\section{Keywords}

medical informatics, medical students, integrated pregraduate and graduate medical education, postgraduate medical education

\section{EJBI 2011; 7(2):58-63}

received: June 17, 2011

accepted: October 3, 2011

published: December 23, 2011

\section{Introduction}

Medical informatics (MI) has for long been recognized by many authors as a special education subject in the medical curriculum [1, 2, 3, 4, 5, 6, 7). Sancho et al wrote "our main objectives when planning a MI course were to give students a general overview of the medical applications of computers and instruct them in the use of computers in future medical practice" 2. Coiera pointed to problem-oriented and careful use of medical records as the important basis for physician's work, however "the problem-oriented medical record is just an information instrument, and clinicians need to know when it is appropriate, and when indeed other formulations might be better choices" [3]. Greenes claims „MI is now appearing on more curricula as a distinct entity" 4. Shortliffe points to the nature of (bio)medical data, saying ,the core issues in the field of MI are those related to the nature of biomedical data and knowledge and their representation and use in computer systems" and, moreover, "from these recurring themes arise a number of research topics in the field", such as experimental planning and verification, data and knowledge acquisition, literature retrieval, diagnosis, treatment planning, human interface, and teach- 
ing 5]. Coiera insists on the need that medical students understand "the dynamic and uncertain nature of medical knowledge" [3]. Also, the medical students should be "able to keep personal knowledge and skills up-to-date", to "assess knowledge according to the statistical basis of scientific evidence", "interpret uncertain clinical data and deal with artifact and error", "structure and analyze clinical decisions in terms of risks and benefits", "apply and adapt clinical knowledge to the individual circumstances of patients", "access, assess, select and apply a treatment guideline, adapt it to local circumstances, and communicate and record variations in treatment plan and outcome", "structure and record clinical data in a form appropriate for the immediate clinical task, for communication with colleagues, or for epidemiological purposes", and communicate by using "the most appropriate communication method for a given task" 3 .

One recent paper states that the MI as a course of study "requires a firm conviction that practicing medicine in the 21st century demands currency, accuracy, and literacy with the available information sources" [8].

Finally, the literature on medical (biomedical or health) informatics education, as well as the Recommendation given by the International Medical Informatics Association (IMIA) [9], clearly outline the preferred content of MI courses. However, detailed programs with clearly defined lectures, seminars, and practicals should be adjusted to specific course of study (medicine, nursing, etc.) and to previous experience of students in the use of information and communication technology (ICT). Another pertinent question is where in the medical curriculum to position the MI courses: at the beginning (first two years), in the middle or at the end (last two years). An alternative view may be the positioning in the medical curriculum does not much matter.

Another challenge was: what MI subjects should be incorporated in the postgraduate medical education level and how to do it.

The aim of this paper is to describe the long time experience of teaching MI at the School of Medicine, University of Zagreb, for medical students at both the integrated pregraduated and graduate (IPG), as well as postgraduate level of medical education.

\section{$2 \mathrm{MI}$ at the IPG Level of Medical Education}

Medical curriculum at the IPG level of education at the School of Medicine, University of Zagreb, has included MI courses starting with the year 1970. From 1970 to 2010, MI changed its position in the medical curriculum several times. It started within the third year of study, was shifted several times to other years (first, second, sixth etc.) and in 2010 its position was established at the fifth year of the medical curriculum. The main reason for these shifts could be explained as "nobody was sure what would be the best position of an MI course in the medical curriculum".
After discussing the question "what is the best position for MI" with colleagues, and relating to experience of teaching MI subjects at the IPG level, we asked the second and the sixth year students about their opinions related to this problem. Their opinion ( $63 \%$ of the second year students) was that the best position for an MI course would be at the end of the medical curriculum. However, $26 \%$ of them suggested the beginning. At the same time, $36 \%$ of the sixth year students voted for the end of curriculum, and $43 \%$ for the beginning [6, 10.

Additional analyses showed that students with little or no experience in the use of ICT voted for the MI course position at the beginning of the medical curriculum. Therefore, our decision was: MI subjects should be split into basics knowledge, which should be set at the beginning of the curriculum, and more specific, medically oriented knowledge was to be set at the end of the medical curriculum [6, 11]. Consequently, the Basics of informatics course was established as an elective course in the first year of study. Medical informatics was established as a mandatory course in the fifth year of study.

Starting with year 2003, the School of Medicine, University of Zagreb, provides also the MD programs for foreign students, so called the Medical Study in English (MSE) (http://mse.mef.hr/). The MSE students come from a number of countries (Australia, USA, Canada, Malaysia, Portugal, South Africa, UK, Sweden, etc.). Regarding the MI courses, the MSE curriculum is the same as the curriculum for Croatian students, with one exception: the Basics of medical informatics is a mandatory course in MSE.

Both Croatian and English medical IPG programs lead to a Doctor of Medicine degree at the School of Medicine, University of Zagreb.

\section{The Aim and Content of MI Courses}

The aim of the Basics of medical informatics course is to enable the students to skilfully and competently use ICT, through practicals in the computer laboratory. The course includes basic terminology, Windows operating system, text processing, spreadsheet software, presentation software and browsers, e-mail and nethics, Internet, and searching engines. Wherever possible, medical examples are used in demonstrating ICT use.

The aims of the Medical informatics course (lectures, seminars, and practicals) are: (1) to introduce the students to the concept of MI, as well as develop their skills in working with health data relevant for practice and research in medicine and health care (coding, structuring, databases); (2) to increase awareness of standards, classifications, data protection, and system security, as well as ethics in the use of ICT; (3) to introduce methods of knowledge discovery as well as the concept ICT-based support for medical decision making; (4) to provide insight into real ICT applications for assessing their appropriate- 
Table 1: The list of courses with medical informatics subjects.

\begin{tabular}{|c|c|c|}
\hline Course & Course subjects & ECTS \\
\hline $\begin{array}{l}\text { Methods in Medical } \\
\text { Informatics }\end{array}$ & $\begin{array}{l}\text { Data structuring and organization; Intelligent data analysis; Simulation mo- } \\
\text { deling; Signal and image processing. }\end{array}$ & 3.5 \\
\hline $\begin{array}{l}\text { Information Sys- } \\
\text { tem Management } \\
\text { and Clinical Data } \\
\text { System }\end{array}$ & $\begin{array}{l}\text { Information system components and infrastructure; Data management; Evalu- } \\
\text { ation of information system. }\end{array}$ & 5 \\
\hline $\begin{array}{l}\text { Knowledge Disco- } \\
\text { very in Medical } \\
\text { Domains }\end{array}$ & $\begin{array}{l}\text { Methodology of knowledge discovery; Hypothesis; Noise detecting; Experimen- } \\
\text { tal and theoretical verification. }\end{array}$ & 5 \\
\hline $\begin{array}{l}\text { Public Health In- } \\
\text { formation System }\end{array}$ & $\begin{array}{l}\text { Public health information needs; Health data sources; Making decision in public } \\
\text { health. }\end{array}$ & 3 \\
\hline Textual Statistics & $\begin{array}{l}\text { Free text in medicine and health care; Codes, categories, theory; Analysis and } \\
\text { interpretation. }\end{array}$ & 5 \\
\hline $\begin{array}{l}\text { Electrophysiological } \\
\text { methods in medical } \\
\text { research }\end{array}$ & $\begin{array}{l}\text { Physiology and electrophysiology; Electrophysiological methods in research; } \\
\text { Electro-medical instrumentation - principles and limitations. }\end{array}$ & 4 \\
\hline Telemedicine & $\begin{array}{l}\text { Telemedical applications; Standards in telemedicine; Evaluation of applications } \\
\text { in telemedicine. }\end{array}$ & 3.5 \\
\hline $\begin{array}{l}\text { Statistical Analysis } \\
\text { of Medical Data }\end{array}$ & $\begin{array}{l}\text { Statistical methodology; Critical reading scientific and professional papers; As- } \\
\text { sessment of appropriateness of applied statistical procedures and presentation } \\
\text { of results in medical literature. }\end{array}$ & 5.5 \\
\hline $\begin{array}{l}\text { Research Methods } \\
\text { in Public Health }\end{array}$ & $\begin{array}{l}\text { Operation research methods and tools; Project design and monitoring; Si- } \\
\text { mulation in public health research. }\end{array}$ & 2 \\
\hline $\begin{array}{l}\text { Evidence } \quad \text { Based } \\
\text { Medicine }\end{array}$ & $\begin{array}{l}\text { Basic principles and methodologies; Critical analysis of literature; Advantages } \\
\text { and limitations. }\end{array}$ & 3.5 \\
\hline
\end{tabular}

ness/usefulness for a practicing physician; and (5) to develop students' skills needed for searching bibliographic databases and other Internet based sources of medical knowledge.

During the course, special attention is given to seminars where students present and discuss experiences described in professional and scientific papers published mostly in international MI journals. Aiming to assess students' opinions about these papers (what was most challenging for them, what could be or has been applicable in the Croatian health system, what could be most of use, etc.) a survey was conducted [12]. Considering the subject, the papers were grouped as: telemedicine, health information system, ICT versus conventional approach (in communication and research), and medical decision support systems.

Students were asked to rank papers according to their attractiveness and usefulness for medical practice. The results showed that telemedicine was ranked as the most attractive. Health information systems achieved the second place. Decision support was the next attractive topic, especially support systems aiming to avoid medical errors, as well as drug information databases. ICT in communication and research was not considered as very attractive.

Taking into account that both telemedicine and computerization of primary health care were the recent projects in Croatia, the first two ranks could be easily explained. However, attractiveness of decision support system showed that students' expectation of MI could not be neglected. It could be concluded that students are motivated to find out how the ICT applications could support their future medical practice.

Discovering such attractive topics could "open the door" to MI and make it interesting and challenging to medical students. Consequently, students might be expected to become active stakeholders in MI research and practice.

\section{$4 \mathrm{Ml}$ at the Postgraduate Education Level}

Postgraduate level of medical education at the School of Medicine in Zagreb started with MI subjects in year 1966. It was then just short information about computers and their potential role in medicine and health care. Five years later the University Computing Center was established in Zagreb, and students were able to get acquainted with some simple applications, mostly examples of statistical data analysis. More recently, MI is a relevant subject in postgraduate education at the University of Zagreb.

Postgraduate education programs at the School of Medicine have been organized as interdisciplinary Doctoral studies in Biomedicine and Health Sciences, lead- 
Table 2: Students' research published from 1994 to 2011. Note: Student's name is in Italic.

\begin{tabular}{|l|l|l|}
\hline \multirow{2}{*}{ Topic } & \multicolumn{2}{|c|}{ Report of student's research published } \\
with his/her mentor and/or others
\end{tabular}

ing to $\mathrm{PhD}$ degree and several professional studies such as Anaesthesiology, Cytology, Diabetology, Epidemiology, Microbiology, Occupational Health, Paediatrics, Public Health, etc., being mostly parts of medical specialization programs.

Some of the professional studies, for example Public Health, Occupational Medicine, and School Medicine, include certain MI subjects, but most of MI issues are subjects of interdisciplinary Doctoral studies. List of courses at the Doctoral study consists of 140 courses, which are either mandatory or elective. Ten of them are related to MI subjects. All but one of MI courses belong to elective group. All of them should be considered as independent, and students can choose one or more of MI courses according to their wishes.

The list of courses related to MI is shown in Table 1.

Statistical Analysis of Medical Data is the only mandatory course in this list. Other courses are usually elected by 5 to 10 students per year (of 50 to 60 enrolled). So far evaluation was undertaken only for the mandatory course and used for course improvement.

\subsection{Students' Research}

Individual program research at the School of Medicine was adjusted to students willing to get more knowledge in MI. It could be practicing at both, IPG and postgraduate level of medical education. Individual student research should finish with a paper or a poster, a master thesis, or a dissertation. Many students do congress or journal papers with their mentors, sometimes as preliminary results of their research, sometimes as a final result. Students' research published from 1994 to 2011 is shown in Table 2.

\section{Discussion}

There is no doubt that ICT is entering into medicine and health care. Effect of computerization the cli- 
nical settings is well documented [48, 49, 50. Benefits of decision support system are remarkable even if just electronically available guidelines were used as support [51, 52, 53, 54, 55, 56].

On the other side, the ICT based medical or health care applications could not be imagined without cooperation of medical profession. Therefore medical professionals should be educated for coming technologies, for changes in their work, for management of changes and management of knowledge.

Several surveys on medical informatics as a discipline, on attitudes of students and medical professionals to this discipline showed to be positive. Some exceptions, like survey on electronic problem lists which showed great variability in attitudes of health professionals [57. However, this result just reflects situation where health professionals were not enough educated or there were not enough co-operations with ICT professionals who use to develop application.

The Croatian experience in medical informatics education programs for medical students based not only to poll, showed positive results. Namely, number of students doing their own research, their student papers, master's and doctoral thesis are the real evidence that medical informatics for medical students were not a missed action.

\section{Conclusion}

The medical students recognize the role of information in their future profession. They feel the medical informatics methods as useful in their professional work (with patients) as well as in research. The special emphasize of their interest is in searching for professional and scientific information, and decision support systems related to medicine and health care.

\section{References}

[1] Hasman A.: Description of Blockcourse in Medical Informatics. Methods Inf Med 1989; 28(4), pp. 239-242.

[2] Shortliffe E.: Medical Informatics meets medical education. Medical Technology. SMR 1999; 1(1), pp. 1-3.

[3] Greenes R.A., Shortliffe E.H.: Medical informatics -- an emerging academic discipline and institutional priority. JAMA 1990; 263, pp. 1114-1120.

[4] Sancho J.J., Gonzalez J.C., Patak A., Sanz F., Sitges-Serra A.: Introducing medical students to medical informatics. Medical Education 1993; 27(6), pp.479-483.

[5] Coierra E.: Medical informatics meets medical education. MJA $1998 ; 168$, pp. 319-320.

[6] Kern J.: Medical Informatics Education -- How to Tailor the Course to Given Stage of Student's Knowledge? AIM 2002; 10 , pp. 59-61.

[7] Berner E.S., Boulware D.W. :Medical Informatics for Medical Students: Not Just Because It's There. MEO 1996;1, p. 3.
[8] Schwarz B.: The Introduction of a Medical Informatics Course into a Medical School Curriculum. Medical Reference Services Quarterly 2011;30(1), pp. 74-82.

[9] Mantas J., Ammenwerth E., Demiris G., Hasman A., Haux R., Hersh W., Hovenga E., Lun K.C., Marin H., MartinSanchez F., Wright G.; IMIA Recommendations on Education Task Force: Recommendations of the International Medical Informatics Association (IMIA) on Education in Biomedical and Health Informatics. First Revision. Methods Inf Med. 2010;49(2), pp.105-120.

[10] Kern J.: Medical informatics in the medical curriculum-when? Stud Health Technol Inform 1999;68, pp. 484-488.

[11] Kern J.: Health and medical informatics in Croatia. Health Info Libr J. 2008;25(4) pp. 302-308.

[12] Kern J, Fišter K, Polašek O, Sović S, Božikov J. What the medical informatics topics are considered as attractive to sixth year students of medicine. Medicinska informatika 2009;9, pp.92100 .

[13] Sonicki Z.: Inductive learning methods in medical decision making and prediction. Zagreb: University of Zagreb, School of Medicine 1994 [Master's thesis].

[14] Vojnić-Zelić D. Parsimonian analytical model for diagnosing knee joint arthrosis. Zagreb: University of Zagreb, School of Medicine 1996 [Master's thesis].

[15] Pikija S.: APGAR prediction based on prenatal data - neural network methodology. Zagreb: University of Zagreb, School of Medicine 1998 [Student's paper].

[16] Lukačić Z.: Fuzzy logic based expert system for prediction in medicine. Zagreb: University of Zagreb, School of Medicine 1998 [Master's thesis].

[17] Markota M.: Data protection in health information system. University of Zagreb, School of Medicine 1999 [Master's thesis].

[18] Fišter K.: A Medical Student for Fellow Medical Students: How We Can Use the Internet to Learn that One Bit More and Have Fun at the Same Time. Poster at the MIE 2000, Hannover 2000 [The best poster of the Congress].

[19] Marinović D.: Attitudes of medical students to ICT in learning the medicine. Zagreb: University of Zagreb, School of Medicine 2009 [Master's thesis].

[20] Božikov J.: Reflection of multistage carcinogenesis model on cancer incidence in human population - example of colorectal cancer. Zagreb: University of Zagreb, School of Medicine 1997 [Doctoral thesis].

[21] Rimac M.: Dynamic simulation model of the cerebral cortex neurogenesis. Zagreb: University of Zagreb, School of Medicine 2002 [Master's thesis].

[22] Manestar-Blažić T. :A simulation model of telomere influence on the development and growth of cancer - testicular seminoma and nonseminoma example. Zagreb: University of Zagreb, School of Medicine 2005 [Master's thesis].

[23] Poljičanin T.: Role of CroDiab registry in prevention of complications in diabetics patients. Zagreb: University of Zagreb, School of Medicine 2010 [Doctoral thesis].

[24] Ilakovac V.: Model of decision support in a hospital. Zagreb: University of Zagreb, School of Medicine 1996 [Master's thesis].

[25] Piberl S.: Mobile ICT in pre-hospital unit of emergency medicine in Health centre Murska Sobota. Zagreb: University of Zagreb, School of Medicine 2011 [Master's thesis].

[26] Lukačić Z., Kern J., Težak-Benčić M.: Detecting predictors of new-born survival by fuzzy sets based machine learning system. Stud Health Technol Inform 2000;77, pp.795-798. 
[27] Lukačić Z., Kern J.: Consistency and reproducibility of attribute extraction by different machine learning systems. Stud Health Technol Inform 2002;90, pp. 316-319.

[28] Vuletić S., Kern J., Sonicki Z., Ivanković D.: Possibilities of See5 software in forecasting of life expectancy not achieving. Stud Health Technol Inform 1999;68, pp.696-699.

[29] Sonicki Z., Morin A., Plasaj T., Sonicki D., Kusić Z.: Redundant thyroid laboratory diagnostic modules in laboratory information system-a way to improve the performance. Stud Health Technol Inform 2000;77, pp. 842-846.

[30] Sonicki Z., Gamberger D., Šmuc T., Sonicki D., Kern J.: Dana mining server - on-line knowledge induction tool. Stud Health Technol Inform 2002;90, pp. 330-334.

[31] Rimac M, Kern J. Prognosis for life expectancy using the inductive learning method. Lijec Vjesn. 1999 ;121(1-2), pp.18-21.

[32] Markota M., Raič G.: Implementing data privacy and security (the Slovenian experience). Stud Health Technol Inform 1997;43, pp. 879-883

[33] Markota M., Kern J., Švab I.: Attitudes towards information system security among physicians in Croatia. Methods Inf Med 200;40(3), pp. 221-224.

[34] Marinović D., Hren D., Sambunjak D., Rašić I., Škegro I., Marušić A., Marušić M.: Transition from longitudinal to block structure of preclinical courses: outcomes and experiences. Croat Med J 2009;50(5), pp.492-506

[35] Rimac M., Božikov J.: Neurogenesis: from experimental dana to system dynamics model. In: Proceedings of the 6th EUROSIM Congress on Modelling and Simulation (Eds. Zupančič B., Karba R., Blažič S.), Vol. 2: Full Papers. Ljubljana, 2007. /CD-ROM/ Ljubljana: EUROSIM/SLOSIM, 2007. Contribution 624,pp.1-8

[36] Manestar-Blažić T., Božikov J. A simulation model of the testicular carcinogenesis. In: Proceedings of the 5th EUROSIM Congress on Modeling and Simulation (Eds. Hamam Y., Attiya G.), Paris, Marne la Vallée, 2004. /CD-ROM/ Paris: EuroSim, 2004.

[37] Manestar-Blažic T., Božikov J.: A simulation of the formation of melanocytic nevi. In: Proceedings of the 6th EUROSIM Congress on Modelling and Simulation (Eds. Zupancic B. Karba R., Blažic S.), Vol. 2: Full Papers. Ljubljana, 2007. /CD-ROM/ Ljubljana: EUROSIM/SLOSIM, 2007. Contribution 568, pp.1-7.

[38] Ilakovac V., Kern J.: An Analysis of the Length of Stay in Hospitals. In: Ceric V, Hljuz-Dobric V(Eds.) In: Proceedings ITI'94, Pula 1994, pp. 423-428.

[39] Andrijašević L., Angebrandt P., Kern J.: Computerization of family practice evaluated by physician. In: Book of Abstracts of the 2nd Croatian Congress on Preventive Medicine and Health Promotion, October 13-16,2010, Zagreb, Croatia, pp.195-196.

[40] Smoljanović L. Similarity measures of parents and children quantitative characteristics, Zagreb: University of Zagreb, School of Medicine 1994 [Master's thesis].

[41] Kujundžić M. Genealogical model of epidemiological dana analysis, Zagreb: University of Zagreb, School of Medcicine 1995 [Master's thesis].

[42] Kujundžić Tiljak M. Genealogical structuring of population and estimation of mortality, Zagreb: University of Zagreb, School of Medicine 2000 [Doctoral thesis].
[43] Šimurina T. Predictive model for postoperative vomiting in patients undergoing general anestesia for laparoscopic gynecological surgery. Zagreb:University of Zagreb, School of Medicine 2011 [Doctoral thesis].

[44] Kujundžić Tiljak M, Kern J, Ivanković D, Tiljak H, Vuletić S. Genealogical structuring of a population. Coll Antropol. 2001;25(1), pp.127-40

[45] Fišter K. Free text analysis. Zagreb: University of Zagreb, School of Medicine 2000. [Student's paper. Rector's award].

[46] Hercigonja-Szekeres M. Value of textual data in observational epidemiological research. Zagreb: University of Zagreb, School of Medicine 2010. [Doctoral thesis].

[47] Hercigonja-Szekeres M, Marinović D, Kern J. Computer laboratory in medical education for medical students. Stud Health Technol Inform. 2009;150, pp.926-30.

[48] Garg A.X., Adhikari N.K., McDonald H., Rosas-Arellano M.P., Devereaux P.J., Beyene J., Sam J., Haynes R.B.: Effects of computerized clinical decision support systems on practitioner performance and patient outcomes: a systematic review. JAMA 2005; 293(10), pp.1223-1238. Review.

[49] Chaudhry B., Wang J., Wu S., Maglione M., Mojica W., Roth E., Morton S.C., Shekelle P.G.: Systematic review: impact of health information technology on quality,efficiency, and costs of medical care. Ann Intern Med 2006;144(10), pp.742-752. Review.

[50] Hersh W.R., Hickam D.H., Severance S.M., Dana T.L., Krages K.P., Helfand M.: Telemedicine for the medicare population: update. Evid Rep Technol Assess (Full Rep) 2006;131, pp.1-41. Review.

[51] Latoszek-Berendsen A., Tange H., van den Herik H.J., Hasman A.: From clinical practice guidelines to computer-interpretable guidelines. A literature overview. Methods Inf Med 2010;49(6), pp.550-70. Review.

[52] van Engen-Verheul M,. de Keizer N., Hellemans I., Kraaijenhagen R., Hasman A., Peek N.: Design of a continuous multifaceted guideline-implementation strategy based on computerized decision support. Stud Health Technol Inform 2010;160, pp. 836-40

[53] Goud R., Hasman A., Strijbis A.M., Peek N.: A parallel guideline development and formalization strategy to improve the quality of clinical practice guidelines. Int J Med Inform 2009;78(8), pp. 513-20.

[54] De Clercq P., Kaiser K., Hasman A.:Computer-Interpretable Guideline formalisms. Stud Health Technol Inform 2008;139, pp.22-43.

[55] Goud R., Hasman A., Peek N.: Development of a guidelinebased decision support system with explanation facilities for outpatient therapy. Comput Methods Programs Biomed 2008;91(2), pp.145-153.

[56] Goud R., Jaspers M.W., Hasman A., Peek N.: Subjective usability of the CARDSS guideline-based decision support system. Stud Health Technol Inform 2008;136, pp.193-198.

[57] Wright A., Maloney F.L., Feblowitz J.C.: Clinician Attitudes Toward and Use of Electronic Problem Lists: A Thematic Analysis. BMC Medical Informatics and Decision Making 2011; 11, p. 36 (available at: http://www.biomedcentral.com/1472-6947/11/36) 